\title{
Ciudadanía y Globalización en América Latina
}

\author{
Juan Monroy García ${ }^{1}$
}

Resumen: En vista de la multiculturalidad en el mundo han excluido al otro o a los otros, y con frecuencia, las minorías han sufrido los atropellos de la discriminación por parte de grupos de poder económico o político. En el presente trabajo abordamos el problema de la exclusión del otro, a partir del tema de la filosofía política de la ciudadanía

Palabras- chave: multiculturalidad - discriminación - minorías

\begin{abstract}
In view of multiculturalism in the world have excluded the other or others, and often, minorities have suffered the abuses of discrimination by groups of economic or political power. In this paper we address the problem of the exclusion of the other, based on the theme of political philosophy of citizenship
\end{abstract}

Keywords: multiculturalism - discrimination - minority

${ }^{1}$ Profesor, Facultad de Humanidades, UAEM. 
Diversas culturas en el mundo han excluido al otro o a los otros, argumentando criterios como cuestiones: étnicas, lingüísticas, religiosas, ideológicas, históricas, territoriales, o políticas. Con frecuencia, las minorías han sufrido los atropellos de la discriminación por parte de grupos de poder económico o político. En el presente trabajo abordamos el problema de la exclusión del otro, a partir del tema de la filosofía política de la ciudadanía; señalamos cómo a lo largo de la historia el reconocimiento de la ciudadanía ha sido negado a diferentes grupos humanos; aunque existe de manera formal la declaración de los derechos humanos —on la inclusión de la ciudadanía, derechos reconocidos por la mayoría de los países-, en los hechos y con frecuencia en varios países este reconocimiento es negado por las elites gobernantes o por los grupos de poder económico.

En torno a la ciudadanía hay por lo menos tres tradiciones teóricas que han estado presentes a lo largo de la historia: la republicana, la liberal y la democrática; entre ellas existen diferencias que se han expresado también en el reconocimiento de los derechos de los miembros de la comunidad. En la tradición republicana, los derechos individuales son asimilados y subordinados al bien público. La existencia de un Estado fuerte, moralmente superior, permite la salvaguardia de los intereses individuales, tal como lo argumentó Hobbes. En cambio, la corriente liberal insiste en la defensa y protección de derechos individuales y universales; el ciudadano requiere de garantías no solamente en su relación con sus conciudadanos sino también frente a los eventuales excesos del Estado. Por último, la tradición democrática abre la vía de solución en dos sentidos. El primero de ellos hace converger voluntad general y bien común, por lo tanto se asemeja a la concepción republicana. El segundo interpreta el concepto de voluntad general a la luz de las exigencias de la participación y del autogobierno. La idea de comunidad ocupa un lugar importante en esa interpretación y da paso al otorgamiento de una variedad de derechos colectivos diferenciados en el seno de una misma entidad política.

Dentro de las características de las tres tradiciones, también cabe mencionar sus diferencias respecto a la concepción de las instituciones políticas. La visión republicana del Estado está marcada por el sello del jacobinismo. Las instituciones centralizan la autoridad, 
educan y movilizan a los ciudadanos y garantizan mediante la homogeneidad cultural, la igualdad en el cuerpo político.

En cambio, en la doctrina liberal clásica, el Estado asume funciones mínimas que son habitualmente asimiladas en un relativo laissez-faire, cuyo límite es la protección de los derechos individuales. La teoría dice poco en cuanto al grado deseable de centralización de la autoridad. Sin embargo, las particularidades de las colectividades siempre se expresan mediante el filtro de los derechos individuales.

Por último, la tradición democrática se divide aquí también entre dos modelos institucionales. El primero presenta fuertes tintes jacobinos y se asimila al ideal de las instituciones republicanas. El segundo, mediante la valoración de la comunidad y de la participación, introduce dimensiones de heterogeneidad y asimetría en la organización política. Las instituciones deben reflejar la multiplicidad de los intereses e identidades mediante arreglos de devolución de poderes hacia las comunidades, grandes o pequeñas. En esa concepción se abre un espacio para fórmulas como el federalismo asimétrico.

A lo largo de la historia, la exclusión del otro o de los otros ha representado un proceso de resistencia y lucha política o social por lograr el reconocimiento de sus derechos. Las mujeres obtuvieron su derecho al voto en los países industriales y en los periféricos después de largas luchas, así como persistentes movilizaciones sociales y políticas. También, el derecho al voto fue restringido por mucho tiempo a los hombres blancos, letrados y propietarios. Durante todo el siglo XX se dieron prolongadas luchas por las conquistas sociales más elementales, como el derecho de la libre asociación de los trabajadores y de los campesinos, el de la libertad de creencias y de expresión, hoy consideradas como libertades elementales y dadas por supuestas en la mayoría de los estados del mundo. Este proceso paulatino de luchas y logros debe apreciarse como un proceso de conquista de la ciudadanía, y de allí surge la convicción de que las democracias modernas son los espacios políticos de los ciudadanos libres e iguales entre sí. Quienes aún no conquistan el derecho de ciudadanía no solamente carecen de algunos derechos elementales, sino que también quedan excluidos del espacio reconocido de la polis o de la civitas. 
A partir de la segunda Guerra Mundial, y con los horrores del fascismo, donde fueron negadas todas las libertades fundamentales, se consolidó un sistema internacional de derechos humanos expresados primeramente en la Declaración Universal de los Derechos Humanos, y posteriormente en la adopción por la Asamblea General de la ONU del Pacto Internacional de Derechos Civiles y Políticos y del Pacto Internacional de Derechos Económicos, Sociales y Culturales, estos dos últimos en el año de 1966. Estos instrumentos jurídicos, junto con otros que se fueron agregando a lo largo de las últimas tres décadas, constituyen lo que actualmente se denomina la Carta Internacional de los Derechos Humanos. Si bien se dice con frecuencia que estos documentos reflejan más que nada una concepción occidentalizada de los derechos humanos, no es menos cierto que a través de las Naciones Unidas se universalizaron estos derechos.

Dos principios fundamentales forman la base del edificio de los derechos humanos en la actualidad: el principio de igualdad de todos los seres humanos ante la ley, y la no discriminación por motivo de género, raza, color o grupo étnico.

A pesar de que estos principios son universalmente aceptados por las naciones, bajo diversas circunstancias los derechos civiles y políticos de los ciudadanos son con frecuencia restringidos, cuando no francamente negados, en nombre de valores superiores o prioritarios, como la unidad nacional, la consolidación del Estado-nación, el desarrollo o el progreso. En una primera etapa, los derechos humanos fueron identificados con el surgimiento de la burguesía como clase hegemónica en las sociedades occidentales. Conforme avanzó el capitalismo sobre amplias regiones del mundo, hasta llegar a la etapa actual de globalización, también se diseminó la ideología de los derechos humanos y, especialmente, la de los derechos civiles y políticos o de ciudadanía.

En el siglo XIX, la filosofía política sostuvo la tesis de que el liberalismo y la democracia tenían mayor posibilidad de desarrollarse en sociedades más homogéneas, que en aquellas divididas internamente o con grandes asimetrías socioeconómicas. Esta apreciación se refería tanto a las desigualdades socioeconómicas, como a las diferencias culturales: étnicas, lingüísticas o religiosas. También Stuart Mill sostuvo que el liberalismo requería de una población culturalmente homogénea para fructificar. 
Por otra parte, hay que destacar que el modelo francés fue imitado por las elites intelectuales latinoamericanas en el siglo XIX, así como en otras partes del mundo. Bajo la inspiración del liberalismo surgió el impulso de la emancipación de las naciones oprimidas por los imperios multinacionales que se habían dividido buena parte del planeta desde el siglo XVI.

Por diversas razones, el imperio español fue el primero en desmoronarse, mientras que el francés y el británico todavía dominaban amplias regiones del planeta, principalmente el continente africano. Cabe señalar que en la propia Europa se dieron desde principios del siglo XIX algunos movimientos nacionalistas, ya sea de unificación como los casos de Alemania e Italia, o de emancipación, como aconteció con los dominios otomano, zarista y austro-húngaro; impulsos que culminaron con el gran movimiento en pro del derecho de las naciones a la libre determinación de los pueblos, derecho consagrado como principio internacional a raíz del Tratado de Versalles.

El nacionalismo basado en cuestiones como lengua, cultura, raíces históricas, territorio, u simplemente con mitos inventados y trasmitidos de generación en generación, constituyó la ideología que dio fundamento a los movimientos nacionalistas emancipatorios o la reconformación en la Europa del siglo XIX.

La construcción de una identidad nacional es una de las tareas asumidas por las élites intelectuales de los diversos países, identidad que es puesta al servicio de las clases dominantes. Este proyecto ha servido para fortalecer la nación contra sus enemigos externos, reales o imaginarios. Esa comunidad inventada que es la nación tiene que distinguirse culturalmente de otras por la lengua, la religión, los mitos y los símbolos cuidadosamente elaborados y trasmitidos de una generación a otra.

En la medida en que el modelo dominante del Estado nacional significa no solamente la unificación territorial, sino también la homogenización, cuando no la uniformización cultural, se han generado tensiones, discordias y a veces conflictos entre el Estado — con su proyecto hegemónico de nación — y aquellos otros grupos y comunidades sociales, culturalmente diferenciados, que no necesariamente comparten la visión hegemónica. 
Hay que tomar en cuenta que, actualmente, la mayoría de la población de las naciones está compuesta de manera heterogénea, bajo diferencias de índole étnico, religioso, lingüístico, racial, siendo éstos los criterios más comunes, o algunos otros que sirven para delimitar y distinguir tales grupos. Las causas y el origen histórico de estas distinciones pueden ser variados: invasiones, conquistas y colonizaciones, migraciones de diversa índole, cambios de fronteras, o bien las cambiantes políticas e ideologías de los gobiernos. Así es como se ha constituido en numerosos estados modernos la cuestión de las minorías, la problemática de los grupos étnicos distintos al grupo dominante o mayoritario. Si bien el concepto de minoría tuvo inicialmente una connotación numérica, desde tiempo atrás se trata por lo común de minorías políticas y sociológicas, independientemente de su peso demográfico en el total de la población.

El problema del otro y la ciudadanía en América Latina

El problema étnico no consiste en la simple coexistencia de etnias diferentes al interior de las fronteras de un Estado-nación, sino en la manera en que esta diversidad es percibida y manejada por las partes involucradas, en el marco del poder del Estado.

En América Latina, la consolidación de las identidades nacionales tomó caminos diferentes. Desde el siglo XIX, el proyecto de nación fue definido por las elites mestizas y criollas bajo sus perspectivas y modelos. Fue la minoría dominante la que se impuso sobre la mayoría preexistente, es decir los pueblos indígenas, su propia concepción de nación, incluyendo su lengua, religión, leyes, instituciones y valores culturales, a tal grado que los pueblos indígenas, emergiendo de tres siglos de coloniaje, no lograron, ni han logrado hasta la fecha, reconocerse ni saberse reflejados en estos nuevos estados-naciones que por lo general les otorgaron la igualdad y la ciudadanía sólo de manera formal. No es extraño entonces que diversos autores han hablado, refiriéndose a nuestras naciones, de unos países formales y de otros reales, de unos países profundos y de otros imaginarios.

Los indígenas no aparecen en los discursos fundadores de las naciones latinoamericanas. Las elites intelectuales han reflexionado desde el siglo XIX, en la búsqueda de la esencia nacional, lo mexicano, lo peruano, lo argentino, etc., tarea a la cual se han dedicado con ahínco filósofos, políticos, literatos, psicólogos y aun militares; por lo general estas reflexiones han excluido a los indígenas y a los negros, así como a otras 
minorías. Se ha pretendido, en América Latina, construir nuevas naciones sin los pueblos indios o a espaldas de ellos. De allí que los procesos de construcción nacional en esta parte del mundo, iniciados desde hace casi dos siglos, sigan sin concluir. Recordemos simplemente que en la mayoría de los países latinoamericanos, a principios del siglo XIX, los pueblos indígenas constituían la mayoría de la población.

En los años sesenta y setenta del siglo XX se dio un polémico debate entre estudiosos latinoamericanos en torno a si la situación de los pueblos indígenas era resultado de su marginación cultural o de su explotación de clase. Siendo los indígenas en su mayoría campesinos pobres, una corriente de pensamiento basado en el análisis marxista de clase opinaba que la pobreza y la marginación de las cuales pendía la caracterización cultural de "indígenas" era resultado de la estructura capitalista, por lo que la solución al entonces llamado "problema indígena" se encontraba en la lucha de clases y la transformación revolucionaria del sistema capitalista.

Otra corriente, hegemónica en las políticas del Estado, opinaba que la situación deplorable de las comunidades indígenas se debía a su marginación cultural del resto de la nación, cuando no de la naturaleza misma de las culturas indígenas consideradas no aptas para el desarrollo, y que la solución se hallaba en un proceso acelerado de "aculturación" bajo la sabia orientación del Estado-nación. Como era de esperarse, los grupos de la izquierda se inclinaron por la primera corriente, derivada del marxismo, mientras que los intelectuales orgánicos del Estado fincaron sus políticas en la segunda.

Por otro lado, a partir de la globalización y del proceso de democratización, la reivindicación del otro o de los otros plantea nuevas dificultades, por la manera como se han relacionado dichos fenómenos, pese a que existe una poderosa tradición teórica occidental, desde el socialismo y el liberalismo, donde se habían pensado como sinónimos del universalismo y la democracia.

El problema consiste en que el escenario actual se plantea en un marco en el que esa relación deseable aparece comprometida, aun cuando su articulación sea el gran desafío de nuestro tiempo. En efecto: ¿es acaso posible discutir de manera realista la democratización fuera del marco de la globalización? Ninguna de las dos tendencias parece dispuesta a 
deponer sus impulsos. El problema es la manera en que podamos resolver las tensiones que ellas generan.

El concepto de ciudadanía, tras una larga etapa de ostracismo dentro de la teoría política, ha recuperado un interés central, en la medida en que sus dimensiones constitutivas remiten tanto a la idea de los derechos universales de las personas cuanto a los problemas de su integración en una comunidad particular. Ambos aspectos permiten recorrer algunos temas cruciales que se expresan en las tensiones entre democratizaciones y globalización a que se ha aludido antes.

En efecto, la ciudadanía supone derechos y obligaciones que se ejercen al interior de una comunidad política. La ciudadanía, en los marcos de la concepción política contemporánea, es por una parte una adscripción — como condición legal— pero también un logro, en la medida en que tiende idealmente a expresarse en formas crecientes de participación de individuos y grupos en la construcción de su destino. Hay en el concepto de ciudadanía un supuesto de autonomía que no puede sino sustentarse en mínimas bases de autonomía social y económica.

Como producto de los movimientos nacionalistas, en América Latina se lograron ciertos derechos sociales; sin embargo, los derechos políticos y civiles no fueron garantizados. Estos desequilibrios produjeron en algunos casos la instauración de regímenes autoritarios en disminución de la participación de la ciudadanía.

Actualmente, en América Latina las elecciones son razonablemente limpias, existen garantías para la difusión de las ideas, para la organización de los partidos políticos, y las autoridades se renuevan periódicamente. Pero hay que señalar que la garantía de estos derechos es relativa, pues el respeto a la ciudadanía política varía aún entre las diversas sociedades latinoamericanas, donde se presentan fenómenos de discutible pureza electoral, tutorías militares, corrupción burocrática y creciente concentración de poderes en el ejecutivo.

Pero estos logros, aunque parciales, de la ciudadanía política coexisten con un sacrificio de las libertades civiles y con una quiebra evidente de los derechos sociales, producto de las agresivas políticas del mercado global. Clásicamente, los derechos civiles 
caracterizan la dimensión liberal de la democracia. Aluden a las libertades y derechos individuales inalienables en el Estado y que suponen la igualdad de las personas ante la ley.

Por cierto que esta idea que guía al Estado de bienestar liberal democrático nació y vivió en el momento de auge de esa experiencia de posguerra en los países centrales y aun, con manifestaciones menos completas y complejas, en los países periféricos. Hoy está, como es obvio, en crisis, arrastrando en su deterioro tanto la práctica de los derechos como el dilema sobre la pertenencia a una comunidad, es decir, las dos caras del concepto de ciudadanía.

Está claro que la ciudadanía política y la conquista de la ciudadanía social se logran a partir de la influencia sobre la toma de decisiones que pudieran tener las mayorías y las diversas minorías sobre los comportamientos del Estado, que estaría dispuesto a intervenir en función de corregir los desequilibrios de una ciudadanía civil fundada en el mercado y en la propiedad privada. Cuando el Estado delega en los grupos de poder económico esas funciones integradoras internas, en medio de la ola de globalización económica actual, es natural que la polarización social crezca.

Una parte de la sociedad está integrada, tiene la noción de pertenecer a una comunidad y ejerce la posibilidad de demandar. Pero cuando otro segmento se encuentra marginado y aun excluido de la sociedad, y sus posibilidades de existencia se ligan al clientelismo del Estado, el conflicto se recrudece y la posibilidad de la rebelión se acentúa.

La discusión es recurrente y recupera el antiguo tópico de la antinomia entre democracias formales y democracias reales. Mientras el pensamiento de izquierda asevera que no existe democracia sin ciudadanía social, el liberalismo sostiene que la democracia es sólo ciudadanía civil y política, que en muchas ocasiones se reduce a lo meramente electoral.

La antinomia entre libertades políticas y justicia social no puede ser resuelta de manera reduccionista. Sin las primeras no existe piso para la democracia, por ello consideramos importante tratar de abatir o por lo menos disminuir las desigualdades socioeconómicas. 
La recuperación de la ciudadanía política fue suficiente bandera para la lucha contra el autoritarismo, pero resulta insuficiente en un mundo que globaliza las sociedades de mercado al precio de excluir o marginar segmentos cada vez mayores de grupos humanos. La constitución plena de la ciudadanía democrática supone la presencia de fuertes tensiones sociales hacia la igualdad: amplia integración de una sociedad civil con capacidad de institucionalización de sus demandas sobre el Estado.

En las condiciones actuales, los indudables avances en materia de democracia política (electoral) se oscurecen por la pérdida de valores republicanos, resultado del deterioro de los controles y los contrapoderes, así como de la modificación del sentido clásico de la representación. Esta degradación de los aspectos republicanos de la democracia es, en realidad, una tendencia generalizada en las sociedades contemporáneas.

El cuadro se completa con la ineficiencia e inequidad en la administración de justicia y de seguridad, tanto en el nivel de los derechos civiles, cuanto en la impunidad que suele proteger los casos de corrupción gubernamental. Si la corrupción de los funcionarios es un problema de ética —esto es, una desviación moral pública o privada—, en cambio, la impunidad - $\mathrm{y}$ su correlato, la inseguridad jurídica - es un problema institucional que atañe a las formas de organización de las relaciones entre Estado y sociedad, a la degradación de la calidad republicana, a la inexistencia de una verdadera división de poderes que permita el juego de los controles y los contrapesos.

A manera de resumen es importante destacar la necesidad de construir nuevas formas de convivencia social, cuya característica fundamental sea el respeto del otro, y la construcción de una nueva ciudadanía no solo formal, sino con características más reales, esta nueva forma de convivencia tendrá que ser respetuosa del pluralismo y las diferencias; donde se tomen en cuenta los acuerdos mayoritarios, pero respetando siempre las opiniones de las minorías.

Punto esencial de estas nuevas formas de convivencia social, es evitar la discriminación de cualquier persona o grupo por motivos económicos, sociales, culturales, religiosos, políticos, o étnicos. La construcción de esta nueva ciudadanía debe partir del bagaje teórico actual, pero proponer cambios profundos en las formas de concebir las 
formas de convivencia social, concediendo singular importancia a la solidaridad cooperación y colaboración entre los seres humanos.

\section{BIBLIOGRAFÍA:}

Alcántara, Manuel y Flavia Freidenberg, (Coordinadores) Partidos políticos de América Latina, tres volúmenes, 2003, FCE-IFE, México.

Baltodano, Mónica, Democratizar la democracia: el desafió de la participación ciudadana, 2002, Graphic Print, Managua.

Cardenal, Ana Sofía y Salvador Puig, (Compiladores), América Central, las democracias inciertas, 1998, Tecnos, Madrid.

Dieterich, Heinz, Globalización, exclusión y democracia en América Latina, 1999, Joaquín Mortiz, México.

Harto de Vera, Fernando, (Compilador), América Latina: desarrollo, democracia y globalización, 2000, Trama editorial / CECAL, Madrid.

Nohlen, Dieter, Sistemas electorales y partidos políticos, 2004, FCE, México.

O’Donell, Guillermo, Osvaldo Iazzetta, y Jorge Vargas Cullell, (Compiladores), Democracia, Desarrollo humano y ciudadanía. Reflexiones sobre la calidad de la democracia en América Latina, Homo Sapiens, Rosario, Argentina, 2003.

Sojo, Carlos (editor), Desarrollo social en América Latina, 2002, FLACSO, San José, Costa Rica.

Steichen, Régine, (compiladora), Democracia y democratización en Centroamérica, 1993, Universidad de Costa Rica, San José, Costa Rica.

Villoro, Luis, Estado plural, pluralidad de culturas, 1999, Paidós UNAM, México. 